OPEN ACCESS

Edited by:

Offer Erez,

Soroka Medical Center, Israel

Reviewed by:

Merih Cetinkaya,

University of Health Sciences, Turkey

Jonathan Michael Davis,

Tufts University, United States

*Correspondence:

Ya-Ying Cheng

chengyy1204@163.com

Specialty section:

This article was submitted to

Neonatology,

a section of the journal

Frontiers in Pediatrics

Received: 02 February 2021

Accepted: 03 September 2021

Published: 29 October 2021

Citation:

Zhou $R$, Zheng $Y-N$, Zhang $X-Y$ and Cheng $Y$-Y (2021) A Meta-Analysis of

the Risk Factors of Persistent

Pulmonary Hypertension in Newborns.

Front. Pediatr. 9:659137.

doi: 10.3389/fped.2021.659137

\section{A Meta-Analysis of the Risk Factors of Persistent Pulmonary Hypertension in Newborns}

\author{
Ran Zhou, You-Ning Zheng, Xin-Ying Zhang and Ya-Ying Cheng* \\ Department of Pediatrics, HeBei General Hospital, Shijiazhuang, China
}

Objective: To determine the risk factors of persistent pulmonary hypertension of the newborn using a meta-analysis method and provide a reference for its clinical prevention and treatment.

Methods: A meta-analysis was performed by searching the PubMed, Embase, Cochrane Library, China Biology Medicine Disc, Wanfang, and Chinese VIP journal databases, as well as the China National Knowledge Infrastructure.

Results: A total of 22 references were included in the meta-analysis; the cumulative medical records comprised 7,937 cases, and 2,613,072 control cases were included. A total of 12 related risk factors were included ( 7 were associated with pregnant women and 5 were associated with newborns).

Conclusion: Among the 12 associated risk factors included, the three most important and their combined odds ratio values and $95 \% \mathrm{Cl}$ were as follows: (1) pregnant women smoking, 4.85 (1.98-11.9) during pregnancy; (2) gestational weeks <37, 4.34 (1.64-11.5); (3) perinatal asphyxia, 3.9 (2.87-5.31).

Keywords: newborn, pulmonary hypertension, risk factors, case control study, meta-analysis

\section{INTRODUCTION}

Persistent pulmonary hypertension of the newborn (PPHN) refers to the persistent increase in pulmonary vascular resistance after birth, resulting in pulmonary artery pressure exceeding the systemic arterial pressure, the right-to-left shunting of blood at the atrial and/or ductal level, severe hypoxia, and other clinical symptoms (1-3). The disease has a high mortality and disability rate in neonatal intensive care units and a high incidence of morbidity in later life. The incidence of PPHN reported in the USA is $\sim 1-5 \%$. However, accurate epidemiological data in this regard are lacking in China (4).

At present, PPHN is not considered a single disease but a clinical syndrome caused by many factors that may be correlated to genetic and environmental factors (5). However, there is no unified understanding of the risk factors and pathogenesis of PPHN. In addition, the early diagnosis of PPHN will be of great significance in terms of follow-up treatment; however, there is currently no method-specific or sufficiently sensitive diagnostic for doing so. This study investigated the risk factors of PPHN by conducting a meta-analysis. 


\section{MATERIALS AND METHODS}

\section{Literature Retrieval Strategy}

This study searched the PubMed, Embase, Cochrane Library, and other foreign electronic databases for relevant articles. Chinese electronic databases, such as China Biology Medicine Disc, Wanfang, Weipu, and China National Knowledge Infrastructure, were also queried. In English, "newborns," "risk factors," "persistent fetal circulation syndrome," and "randomized controlled trial" were employed as subject headings, and a combination of subject and free-text terms were used to conduct searches. The Chinese search words were as follows: “新生 儿” (newborns), “持续性肺动脉高压” (persistent pulmonary hypertension), and “危险因素” (risk factors).

\section{Literature Selection and Literature Quality Evaluation}

\section{Literature Selection}

The inclusion criteria related to database journals were as follows: case-control studies on the risk factors of developing PPHN; all cases were confirmed PPHN; the sample size was provided; odds ratio (OR) value and a $95 \%$ CI were provided or data in the text could be converted into OR value and a 95\% CI; the relevant journal was written in Chinese or English.

The exclusion criteria were as follows: the journal articles were reviews or a meta-analysis; articles related to individual cases or that lacked control groups; duplicate documents; articles with incomplete data or where the full text was unavailable.

Two independent investigators reviewed each of the studies and determined if they should be included based on the inclusion and exclusion criteria, and disagreements between them were resolved through a third party or by both parties.

\section{Quality Evaluation of the References}

The Newcastle-Ottawa scale was used to evaluate the methodological quality of the included references. The results are shown in Table $\mathbf{1 .}$

\section{Data Acquisition and Processing}

The "double independent extraction method" was performed. The references were extracted by two evaluators according to the data collection table (Table 1), and controversial data were explored using a third investigator or jointly by both investigators to determine whether they should be included. Dichotomous data considered the OR as the effect size; based on whether the same measure was adopted for the continuous variable, the mean difference or the standardized mean difference was used as the effect size. The Revman 5.3 software (https://training. cochrane.org/online-learning/core-software-cochrane-reviews/ revman/revman-5-download) program was used to merge effect sizes and to analyze the heterogeneity of the included data. If no heterogeneity was detected ( $\mathrm{p}>0.1$ and $I^{2}<30 \%$ ), the fixed-effects model was directly applied. If heterogeneity was detected $\left(p<0.1\right.$ or $I^{2}>30 \%$ ), the random-effects model was used. The Beggar method was adopted to analyze the publication bias of the included studies.

\section{RESULTS}

\section{Literature Retrieval Result}

A total of 108 related references were retrieved according to the adopted retrieval strategy; 27 articles were initially included after reading the title, abstract, and full text of the references, and five references with incomplete data were excluded. A total of 22 articles were finally included in this study, all of which represented case-control studies. In total, there were 7,937 case records and 2,613,072 control cases. The process chart for the inclusion of articles is presented in Figure 1, and the basic background of these references is presented in Table $\mathbf{1}$.

\section{The Combined Literature and Heterogeneity Test Results}

The included references were combined according to the 12 potential risk factors of PPHN. The applied effect model was selected based on the heterogeneity, in which $\mathrm{p}>0.1$ and $I^{2}<30 \%$ indicated no heterogeneity, $0.01<p<0.1$ or $30 \%$ $<I^{2}<60 \%$ indicated middle heterogeneity, and $0<p<$ 0.01 or $60 \%<I^{2}$ indicated larger heterogeneity. The fixed-effects model was selected for cases with no heterogeneity, while the random-effects model was selected for cases with heterogeneity (Table 2).

\section{Combined Risk Factors}

\section{The Risk Factors Related to Pregnant Women}

In this study, seven major risk factors were found to be associated with pregnant women, i.e., age, body mass index, unipara, pregnancy-induced hypertension syndrome, gestational diabetes mellitus, smoking, and the use of selected prescription drugs. A history of smoking included pre-pregnancy and mid-pregnancy smoking, and prescription drug use included steroid hormones, selective serotonin reuptake inhibitors (SSRIs), and other antidepressants. The OR values of the aforementioned risk factors were combined, and the publication bias and sensitivity were analyzed and calculated. The results are presented in Table 3.

The combined OR value of the seven risk factors was $>1$. The most important risk factors were smoking, both pre- and midpregnancy (pre-pregnancy), and pregnant women with diabetes. The combined OR and 95\% CI values were 4.85 (1.98-11.90) and 3.61 (2.02-6.45), respectively. Publication bias and sensitivity analyses were carried out for the seven combined risk factors, which were found to be free of publication bias and were consistent in terms of sensitivity.

\section{Risk Factors Associated With Newborns}

Five risk factors associated with newborns were included in the present study, i.e., male gender, perinatal asphyxia, gestational weeks $<37$, gestational weeks $>42$, and cesarean delivery. The most important risk factor was gestational weeks $<37$, and the combined OR and 95\% CI value was 4.34 (1.64-11.50). Publication bias and sensitivity analyses were carried out for the five combined risk factors, which were found to be free of publication bias and consistent in terms of sensitivity (Table 4). 
TABLE 1 | The basic situation of these literatures.

\begin{tabular}{|c|c|c|c|c|c|c|}
\hline No. & First author & Published time & Place & Number in the observation groups & Number in the control groups & NOS score \\
\hline 1 & Reece (6) & 1987 & US & 37 & 150 & 7 \\
\hline 2 & Van Marter (7) & 1996 & US & 138 & 298 & 9 \\
\hline 3 & Bearer (8) & 1997 & US & 31 & 39 & 6 \\
\hline 4 & Muraskas (9) & 2001 & US & 15 & 36 & 7 \\
\hline 5 & Chambers (10) & 2006 & US & 337 & 836 & 7 \\
\hline 6 & Kallen (11) & 2008 & Sweden & 2,006 & 830,818 & 9 \\
\hline 7 & Araujo (12) & 2008 & Brazil & 43 & 130 & 7 \\
\hline 8 & Andrade (13) & 2009 & US & 1,104 & 1,104 & 8 \\
\hline 9 & Cai (14) & 2010 & China & 45 & 82 & 7 \\
\hline 10 & Li (13) & 2011 & China & 57 & 114 & 7 \\
\hline 11 & Li (15) & 2011 & China & 80 & 80 & 8 \\
\hline 12 & Wilson (9) & 2011 & US & 20 & 120 & 8 \\
\hline 13 & Liang (16) & 2011 & China & 40 & 103 & 9 \\
\hline 14 & Delaney (17) & 2012 & US & 337 & 846 & 8 \\
\hline 15 & Yang (18) & 2013 & China & 57 & 114 & 7 \\
\hline 16 & Shen (19) & 2013 & China & 41 & 41 & 7 \\
\hline 17 & Qi (20) & 2014 & China & 92 & 92 & 8 \\
\hline 18 & Wang (21) & 2014 & China & 57 & 63 & 7 \\
\hline 19 & Lee (22) & 2014 & Korea & 28 & 32 & 8 \\
\hline 20 & Li (23) & 2015 & China & 50 & 50 & 8 \\
\hline 21 & Du (24) & 2016 & China & 45 & 45 & 7 \\
\hline 22 & Steurer (25) & 2017 & US & 3,277 & $2 E+06$ & 8 \\
\hline
\end{tabular}

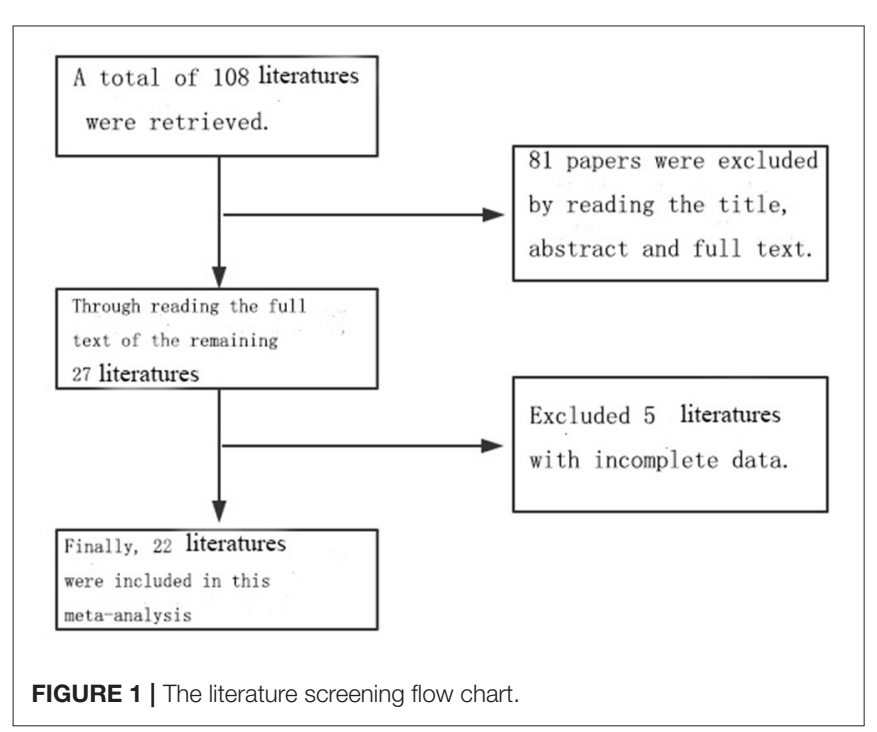

\section{DISCUSSION}

Persistent pulmonary hypertension of the newborn remains one of the main causes of postnatal death. In addition, lacking data for improving awareness of the factors that influence the early diagnosis and prevention of PPHN increases the risk of developing the condition. At present, the risk factors for PPHN are not fully understood and several of these risks remain controversial. Clarifying the risk factors of PPHN is not only of significance to the prevention of PPHN but can also provide awareness for early clinical detection and diagnosis of the condition.

Among the 12 risk factors in this study, 8 associated with an $\mathrm{OR}>2$ were pre-pregnancy and mid-pregnancy smoking, gestational weeks $<37$, perinatal asphyxia, pregnant women with diabetes, the age of pregnant women being $>30$, pregnant women with pregnancy-induced hypertension (PIH), and cesarean delivery.

The mechanism of PPHN caused by pregnant women who smoked may be correlated to the presence of nicotine in tobacco. According to a study conducted by Bearer et al. (8), cotinine and the metabolites of nicotine in the human body can rapidly accumulate in the fetus through entry via the placenta. In addition, a fetal liver does not have the ability to metabolize cotinine; hence, the half-life of cotinine in the uterus is prolonged. In addition, the decrease in blood oxygen content caused by smoking pregnant women is also a risk factor for PPHN. According to a study conducted by Van Marter et al. (25), low blood oxygen content in pregnant women can cause the muscle layers of neonatal arterioles to overdevelop before birth. Under hypoxia stimulation, pulmonary arteriole spasm leads to a continuous increase in pulmonary artery pressure and an increase in pulmonary artery resistance. Factors such as a total gestational period of $\leq 37$ weeks, perinatal asphyxia, pregnant women with diabetes, pregnant women aged above 30, and pregnant women with PIH may affect the blood supply of the placenta to the fetus and lower the fetal blood oxygen concentration. Furthermore, fetal lung 
TABLE 2 | The combined literature and heterogeneity test results.

\begin{tabular}{|c|c|c|c|c|c|c|}
\hline Risk factors & The number of literatures & References & $\boldsymbol{P}$ & $I^{2}$ & Heterogeneity & Effect model \\
\hline $\mathrm{BMl}>27$ & 6 & $(10,13,20,22-24)$ & 0.42 & $13.30 \%$ & No & Fixed \\
\hline Age $>30$ & 6 & $(10,13,20,22-24)$ & 0.34 & $15.20 \%$ & No & Fixed \\
\hline Pregnancy-induced hypertension syndrome & 8 & $(9,13,16,18-20,23,25)$ & 0.07 & $49.50 \%$ & Middle & Random \\
\hline Gestational diabetes mellitus & 9 & $(8,10,13,16,18-20,24,26)$ & 0.03 & $52.80 \%$ & Middle & Random \\
\hline Smoking & 8 & $(7,10,13,17,22,24-26)$ & 0.14 & $29.20 \%$ & No & Fixed \\
\hline Taking drugs & 10 & $(7,9-11,13,14,17,24-26)$ & 0.5 & $10.60 \%$ & No & Fixed \\
\hline Unipara & 5 & $(9,13,17,22,24)$ & 0.29 & $21.60 \%$ & No & Fixed \\
\hline Newborn gender & 11 & $(7-10,13,15,18,19,24-26)$ & $<0.01$ & $81.80 \%$ & Larger & Random \\
\hline Neonatal asphyxia & 11 & $(8,9,15-21,23,25,26)$ & 0.07 & $33.80 \%$ & Middle & Random \\
\hline Gestational weeks > 42 & 6 & $(9,15,20,22,23,26)$ & 0.36 & $22.20 \%$ & No & Fixed \\
\hline Cesarean delivery & 13 & $(6,9,13,15,18-21,23-26)$ & 0.15 & $10.40 \%$ & No & Fixed \\
\hline Gestational weeks <37 & 8 & $(13,15,16,18,19,22,25,26)$ & 0.25 & $9.10 \%$ & No & Fixed \\
\hline
\end{tabular}

TABLE 3 | Risk factors present in pregnant women.

\begin{tabular}{|c|c|c|c|c|c|c|c|}
\hline \multirow[t]{2}{*}{ Risk factors } & \multirow{2}{*}{$\begin{array}{l}\text { Combined } \\
\text { quantity }\end{array}$} & \multirow{2}{*}{$\begin{array}{l}\text { Effect } \\
\text { model }\end{array}$} & \multirow{2}{*}{$\begin{array}{l}\text { Combined } \\
\text { OR value }\end{array}$} & \multicolumn{2}{|c|}{$95 \% \mathrm{Cl}$} & \multirow{2}{*}{$\begin{array}{l}\text { Publication } \\
\text { bias }\end{array}$} & \multirow{2}{*}{$\begin{array}{l}\text { Sensitivity } \\
\text { analysis }\end{array}$} \\
\hline & & & & Lower limit & Upper limit & & \\
\hline $\mathrm{BMl}>27$ & 6 & Random & 1.32 & 0.92 & 1.89 & No & Consistent \\
\hline Age $>30$ & 6 & Random & 2.8 & 0.36 & 2.93 & No & Consistent \\
\hline $\mathrm{PIH}$ & 8 & Random & 2.42 & 0.73 & 8.05 & No & Consistent \\
\hline Gestational diabetes mellitus & 9 & Random & 3.61 & 2.02 & 6.45 & No & Consistent \\
\hline Pre-pregnancy and mid-pregnancy smoking & 8 & Random & 4.85 & 1.98 & 11.9 & No & Consistent \\
\hline Taking drugs & 10 & Random & 2.39 & 1.25 & 4.57 & No & Consistent \\
\hline Unipara & 5 & Random & 1.16 & 1.09 & 1.23 & No & Consistent \\
\hline
\end{tabular}

TABLE 4 | Risk factors present in newborns.

\begin{tabular}{|c|c|c|c|c|c|c|c|}
\hline \multirow[t]{2}{*}{ Risk factors } & \multirow{2}{*}{$\begin{array}{l}\text { Combined } \\
\text { quantity }\end{array}$} & \multirow{2}{*}{$\begin{array}{l}\text { Effect } \\
\text { model }\end{array}$} & \multirow{2}{*}{$\begin{array}{l}\text { Combined } \\
\text { OR value }\end{array}$} & \multicolumn{2}{|c|}{$95 \% \mathrm{Cl}$} & \multirow{2}{*}{$\begin{array}{l}\text { Publication } \\
\text { bias }\end{array}$} & \multirow{2}{*}{$\begin{array}{l}\text { Sensitivity } \\
\text { analysis }\end{array}$} \\
\hline & & & & Lower limit & Upper limit & & \\
\hline Baby boy & 11 & Random & 1.84 & 1.28 & 2.63 & No & Consistent \\
\hline Neonatal asphyxia & 11 & Random & 3.9 & 2.87 & 5.31 & No & Consistent \\
\hline Gestational weeks <37 & 8 & Random & 4.34 & 1.64 & 11.5 & No & Consistent \\
\hline Gestational weeks > $>42$ & 6 & Random & 1.75 & 0.97 & 3.18 & No & Consistent \\
\hline Cesarean delivery & 13 & Random & 2.06 & 1.34 & 3.15 & No & Consistent \\
\hline
\end{tabular}

development is affected by chronic hypoxia of the fetus in the uterus (7).

Premature infants are prone to neonatal respiratory distress syndrome. Due to the insufficient secretion of alveolar surfactant, the development of pulmonary vessels and parenchymal tissue is inferior to that of full-term infants; accordingly, the ventilation function of premature infants is weak, and pulmonary artery spasm and other phenomena can easily occur, leading to the increased or even continued increase of pulmonary artery pressure and other risks. Among the risk factors of PPHN in late pregnancy, existing research (27) included placental abscess, preeclampsia, intrauterine growth restriction, and other diseases; the risk factors selected in this study included preeclampsia, and pregnancy combined with diabetes.
The full-term newborns of diabetic mothers tend to be heavier. Some studies (28) reported that heavier fetuses also had a higher incidence of PPHN because heavier children consume more oxygen, which further increases the incidence of pulmonary hypertension. Preeclampsia can cause fetal chronic intrauterine hypoxia; furthermore, intrauterine chronic hypoxia and perinatal asphyxia can lead to neonatal hypoxia and acidosis in the body, pulmonary arteriole endothelial damage, and artery deformation and mechanization; this can, in turn, lead to increased pulmonary artery pressure. As a result, hypoxia can become aggravated, and the pulmonary arteriole can continue to spasm, leading to the formation of PPHN.

An increasing amount of evidence suggests that the type of newborn delivery is also a risk factor for developing PPHN. A 
case-control study based on 9,452 infants in the USA showed that the risk of PPHN among cesarean section delivery was five times higher than in cesarean section with rates of $0.5 \%(42 / 8,388)$ and $0.09 \%(1 / 1,064)$, respectively (13). The increased risk of PPHN during a cesarean section may be (29) related to prostaglandins; this type of delivery can reduce the level of prostaglandins in newborns, which acts as the main vasoactive factor for infants to quickly adapt to the uterine environment after birth (7). In addition, a cesarean section does not include natural birth canal extrusion; as a result, residual amniotic fluid in the interstitium of the newborn's lungs will impact the amount and function of lung surface-active substances, thereby affecting the contraction and diastole of the alveoli.

In addition to the previously noted risk factors, the incidence of PPHN in male infants is higher than in female infants; the combined OR and 95\% CI was 1.84 (1.28-2.63). The analysis presented herein is consistent with the existing literature in this regard, which may be related to the lower maturity of male lung development in the neonatal period, making male infants more prone to suffering from PPHN compared with female infants. Steroid use during pregnancy and SSRI-type antidepressants are also risk factors for PPHN, but the specific mechanism(s) involved remains unclear. Current evidence suggests that the use of SSRIs during late pregnancy increases the risk of newborns developing PPHN (30-32).

In summary, PPHN is a disease caused by a combination of multiple factors. Reducing adverse factors in the perinatal period and actively intervening to correct metabolic disorders

\section{REFERENCES}

1. Konduri GG. New approaches for persistent pulmonary hypertension of newborn. Clin Perinatol. (2004) 31:591-611. doi: 10.1016/j.clp.2004.04.001

2. Lipkin PH, Davidson D, Spivak L, Straube R, Rhines J, Chang CT. Neurodevelopmental and medical outcomes of persistent pulmonary hypertension in term newborns treated with nitric oxide. J Pediatr. (2002) 140:306-10. doi: $10.1067 / \mathrm{mpd} .2002 .122730$

3. Keller RL. Pulmonary hypertension and pulmonary vasodilators. Clin Perinatol. (2016) 43:187-202. doi: 10.1016/j.clp.2015.11.013

4. Lakshminrusimha S, Keszler M. Persistent pulmonary hypertension of the newborn. Neoreviews. (2015) 16:680-92. doi: 10.1542/neo.16-12-e680

5. Alwan S, Bandoli G, Chambers CD. Maternal use of selective serotoninreuptake inhibitors and risk of persistent pulmonary hypertension of the newborn. Clin Pharmacol Ther. (2016) 100:34-41. doi: 10.1002/cpt.376

6. Reece EA, Moya F, Yazigi R, Holford T, Duncan C, Ehrenkranz RA. Persistent pulmonary hypertension: assessment of perinatal risk factors. Obstet Gynecol. (1987) 70:696-700.

7. Wilson KL, Zelig CM, Harvey JP, Cunningham BS, Dolinsky BM, Napolitano PG. Persistent pulmonary hypertension of the newborn is associated with mode of delivery and not with maternal use of selective serotonin reuptake inhibitors. Am J Perinatol. (2011) 28:19-24. doi: 10.1055/s-0030-1262507

8. Bearer C, Emerson RK, O'Riordan MA, Roitman E, Shackleton C. Maternal tobacco smoke exposure and persistent pulmonary hypertension of the newborn. Environ Health Perspect. (1997) 105:202-6. doi: 10.1289/ehp.97105202

9. Muraskas JK, Juretschke LJ, Weiss MG, Bhola M, Besinger RE. Neonatalperinatal risk factors for the development of persistent pulmonary hypertension of the newborn in preterm newborns. Am J Perinatol. (2001) 18:87-91. doi: 10.1055/s-2001-13638 after birth, as well as avoiding excessive intrathoracic pressure, are key aspects for reducing the incidence of PPHN. All 12 risk factors included in this study can be considered as relevant risk factors for PPHN, and attention should be paid to newborns with multiple risk factors in clinical practice to provide better awareness for the early diagnosis of PPHN. The risk that cesarean section delivery poses for developing PPHN should be considered when selecting the mode of delivery. Pregnant women should also try to avoid or reduce the use of steroids and SSRI drugs during pregnancy.

\section{DATA AVAILABILITY STATEMENT}

The original contributions presented in the study are included in the article/supplementary material, further inquiries can be directed to the corresponding author.

\section{AUTHOR CONTRIBUTIONS}

RZ conceptualized and designed the study, drafted the initial manuscript, reviewed, and revised the manuscript. Y-NZ and X-YZ designed the data collection instruments, collected data, carried out the initial analyses, reviewed, and revised the manuscript. Y-YC coordinated and supervised data collection and critically reviewed the manuscript for important intellectual content. All authors approved the final manuscript as submitted and agree to be accountable for all aspects of the work.

10. Chambers CD, Hernandezdiaz S, Van Marter LJ, Werler MM, Louik C, Jones KL, et al. Selective serotonin-reuptake inhibitors and risk of persistent pulmonary hypertension of the newborn. N Engl J Med. (2006) 354:57987. doi: 10.1056/NEJMoa052744

11. Källén B, Olausson PO. Maternal use of selective serotonin re-uptake inhibitors and persistent pulmonary hypertension of the newborn. Pharmacoepidemiol Drug Saf. (2008) 17:801-6. doi: 10.1002/pds.1570

12. Steurer MA, Jelliffe-Pawlowski LL, Baer RJ, Partridge JC, Rogers EE, Keller RL. Persistent pulmonary hypertension of the newborn in late preterm and term infants in California. Pediatrics. (2017) 139:116578. doi: 10.1542/peds.2016-1165

13. Araujo OR, Albertoni AC, Lopes VA, Louzada ME, Lopes AO, Cabral $\mathrm{EA}$, et al. Cesarean deliveries and other risks for persistent pulmonary hypertension of the newborn. Rev Bras Ter Intensiva. (2008) 20:3947. doi: 10.1590/S0103-507X2008000400012

14. Andrade SE, Mcphillips H, Loren D, Raebel MA, Lane K, Livingston J, et al. Antidepressant medication use and risk of persistent pulmonary hypertension of the newborn. Pharmacoepidemiol Drug Saf. (2009) 18:24652. doi: $10.1002 / \mathrm{pds} .1710$

15. Du LL, Wang J, Chen J, Xiang JW, Liang S. Risk factors of neonatal pulmonary hypertension. Guangxi Med. (2016) 38:496-8. doi: 10.11675/j.issn.0253-4304.2016.04.14

16. Li SQ, Liu QY, Zhou SF, Zhang ST. Clinical analysis of 80 cases of neonatal pulmonary hypertension. Chin J Community Med. (2011) 13:95-7. doi: 10.3969/j.issn.1007-614x.2011.09.094

17. Delaney C, Cornfield DN. Risk factors for persistent pulmonary hypertension of the newborn. Pediatrics. (2007) 120:272-82. doi: 10.1542/peds.2006-3037

18. Cai WH. Risk factors analysis of neonatal meconium inhalation syndrome complicated with persistent pulmonary hypertension. J Occup Health. (2010) 16:25-6. Liang Hong, Mai Haishan, Zhou Wei, Zhang Zhe 
19. Liang H, Mai HS, Zhou W, Zhang Z. Risk factors of neonatal sustained pulmonary hypertension. Chin J Med. (2011) 46:70-3. doi: 10.3969/j.issn.1008-1070.2011.02.026

20. Li XY, Shen MP, Gong HM, Zhang B, Jia DM. Risk factors of neonatal pulmonary hypertension. J Clin Pulm Med. (2015) 20:1070-3. doi: 10.3969/j.issn.1009-6663.2015.06.033

21. Qi YJ, Liu H, Wu HL, Weng JW, Dong SX, Jin F, et al. Analysis of related factors of pulmonary hypertension after neonatal asphyxia resuscitation. Chin J Paediatrics. (2014) 29:1177-9. doi: 10.3760/j.issn.2095-428X.2014.15.015

22. Lee EC, Min GC, Shim GH, Song YH, Chey MJ. Comorbid risk factors of persistent pulmonary hypertension of the newborn in infants with meconium aspiration syndrome. Neonatal Med. (2014) 21:16671. doi: 10.5385/nm.2014.21.3.166

23. Yang CF, Xu CY, Li YM. Clinical analysis of high risk factors of secondary neonatal pulmonary hypertension. Chin Pediatr Emerg Med. (2013) 20:523-5. doi: 10.3760/cma.j.issn.1673-4912.2013.05.027

24. Li YM, Yan CY, Yang CF, Dai CL. Clinical study on high risk factors of 57 cases of persistent pulmonary hypertension of the newborn. Int Conf Bioinform Biomed Eng. (2011) 19:378-80. doi: 10.1109/HHBE.2011.6027977

25. Van Marter LJ, Leviton A, Allred EN, Pagano M, Sullivan KF, Cohen A, et al. Persistent pulmonary hypertension of the newborn and smoking and aspirin and non-steroidal antiinflammatory drug consumption during pregnancy. Pediatrics. (1996) 97:658-63. doi: 10.1097/00006254-199611000-00010

26. Wang LM. Analysis of risk factors associated with secondary pulmonary hypertension in newborns. Mod Diagn Treat. (2014) 25:1642-3.

27. Zhang X. Analysis of the clinical effect of milrinone in the treatment of newborns persistent pulmonary hypertension. World Latest Med Inf. (2019) 19:169-71. doi: 10.19613/j.cnki.1671-3141.2019.67.111

28. Cao MY. Application progress of hematological index examination in the diagnosis of pulmonary hypertension. Med Forum. (2019) 23:36834. doi: 10.19435/j.1672-1721.2019.25.081
29. Shen MP, Li XY, Jia DM. Logistic regression analysis of risk factors of neonatal pulmonary hypertension. Chin J Pediatrics. (2013) 28:1405-8. doi: 10.3760/cma.j.issn.2095-428X.2013.18.013

30. Listed N, SSRI. Antidepressants and persistent pulmonary hypertension in newborns. Prescrire Int. (2008) 17:156.

31. Bérard A, Sheehy O, Zhao JP, Vinet É, Bernatsky S, Abrahamowicz M. SSRI and SNRI use during pregnancy and the risk of persistent pulmonary hypertension of the newborn. Br J Clin Pharmacol. (2017) 83:112633. doi: $10.1111 /$ bcp. 13194

32. Casper RC. Use of selective serotonin reuptake inhibitor antidepressants in pregnancy does carry risks, but the risks are small. J Nerv Ment Dis. (2015) 203:167-9. doi: 10.1097/NMD.0000000000000258

Conflict of Interest: The authors declare that the research was conducted in the absence of any commercial or financial relationships that could be construed as a potential conflict of interest.

Publisher's Note: All claims expressed in this article are solely those of the authors and do not necessarily represent those of their affiliated organizations, or those of the publisher, the editors and the reviewers. Any product that may be evaluated in this article, or claim that may be made by its manufacturer, is not guaranteed or endorsed by the publisher.

Copyright (c) 2021 Zhou, Zheng, Zhang and Cheng. This is an open-access article distributed under the terms of the Creative Commons Attribution License (CC BY). The use, distribution or reproduction in other forums is permitted, provided the original author(s) and the copyright owner(s) are credited and that the original publication in this journal is cited, in accordance with accepted academic practice. No use, distribution or reproduction is permitted which does not comply with these terms. 